\title{
A generalized fractional (q,h)-Gronwall inequality and its applications to nonlinear fractional delay (q,h)-difference systems
}

\author{
Feifei $\mathrm{Du}^{1}$ and Baoguo Jia ${ }^{2}$ \\ ${ }^{1}$ Shanghai Jiao Tong University \\ ${ }^{2}$ Sun Yat-Sen University
}

October 30, 2020

\begin{abstract}
In this paper, a generalized fractional $\$(\mathrm{q}, \mathrm{h}) \$$-Gronwall inequality is investigated. Based on this inequality, we derive the uniqueness theorem and the finite-time stability criterion of nonlinear fractional delay $\$(\mathrm{q}, \mathrm{h}) \$$-difference systems. Several examples are given to illustrate our theoretical result.
\end{abstract}

\section{Hosted file}

Monotonicity_fractional_integral.pdf available at https://authorea.com/users/342073/ articles/489922-a-generalized-fractional-q-h-gronwall-inequality-and-its-applicationsto-nonlinear-fractional-delay-q-h-difference-systems 